\title{
CD34+/CD144+ Circulating Endothelial Cells as an Indicator of Carotid Atherosclerosis
}

\author{
Takamichi Sugimoto, MD, PhD, ${ }^{*}+$ Naohisa Hosomi, MD, PhD, ${ }^{*}$ Tomohisa Nezu, MD, ${ }^{*}$ \\ Tetsuya Takahashi, MD, PhD, ${ }^{*}$ Shiro Aoki, MD, PhD, ${ }^{*}$ Ikuko Takeda, MD, PhD, ${ }^{*}$ \\ Tomoya Mukai, MD, Kazuhide Ochi, MD, PhD, ${ }^{*}$ Takeshi Kitamura, MD, PhD, + \\ Toshiho Ohtsuki, MD, PhD, $\ddagger$ and Masayasu Matsumoto, MD, $\mathrm{PhD}^{*}$
}

Circulating endothelial cells (CECs) and endothelial progenitor cells (EPCs) are 2 populations of endothelioid cells present in the blood. ${ }^{1}$ CECs have mainly been studied in the fields of oncology and immunology, 2,3 and EPCs were discovered in and isolated from the peripheral blood of human adults. ${ }^{4}$ Blood biomarkers
From the *Department of Clinical Neuroscience and Therapeutics, Hiroshima University Graduate School of Biomedical and Health Sciences, Hiroshima; +Department of Neurology, Chugoku Rosai Hospital, Kure; and †Stroke Center, Kindai University Hospital, Osaka-Sayama, Japan.

Received August 26, 2014; revision received October 1, 2014; accepted October 2, 2014.

This study was supported in part by research grants from the Ministry of Health, Labour and Welfare, Japan, the Japan Science and Technology Agency, the Smoking Research Foundation, the Tsuchiya Foundation, and the Japan Heart Foundation.
The authors declare no conflicts of interest.

Address correspondence to Naohisa Hosomi, MD, PhD, Department of Clinical Neuroscience and Therapeutics, Hiroshima University Graduate School of Biomedical and Health Sciences, 1-2-3 Kasumi, Minami-ku, Hiroshima 734-8551, Japan. E-mail: nhosomi@ hiroshima-u.ac.jp.

1052-3057/\$ - see front matter

(C) 2014 by National Stroke Association

http:/ / dx.doi.org/10.1016/j.jstrokecerebrovasdis.2014.10.001 
have been studied in patients with ischemic stroke, ${ }^{5-7}$ and several studies have reported that the number of EPCs is related to certain indicators of atherosclerosis, such as intima-media thickness (IMT) in healthy adults ${ }^{8}$ and brachial artery flow-mediated dilatation (FMD) in patients with cardiovascular risk factors. ${ }^{9}$

Ultrasonography that enables quantification of arterial wall thickness and the size of atherosclerotic lesions in the carotid arteries is commonly used as a clinical tool for evaluating atherosclerosis because carotid arteriosclerosis is regarded as an indicator of generalized atherosclerosis. ${ }^{10,11}$ Persson et $\mathrm{al}^{12}$ showed that ultrasonographic and microscopic IMT measurements were closely correlated. Increased carotid arterial wall thickness is also related to the prevalence of myocardial infarction, angina pectoris, cerebrovascular disease, and peripheral vascular disease and is associated with risks of stroke and myocardial infarction. ${ }^{13-17}$

To our knowledge, 2 studies have evaluated the relationship of CECs or EPCs with indicators of carotid atherosclerosis, such as IMT or the plaque score, in acute ischemic stroke with an ischemic response or inflammation. ${ }^{18,19}$ This ischemic response or inflammation may influence the number of CECs or EPCs in the blood. The relationship of the number of CECs or EPCs with indicators of carotid atherosclerosis has not been clarified in patients with chronic ischemic stroke. The objective of this study was to investigate the relationship between the number of CECs or EPCs, as determined using flow cytometry, and indicators of carotid atherosclerosis in patients with chronic ischemic stroke and in patients with risk factors for stroke.

\section{Subjects and Methods}

This study was approved by the Ethics Committee of Hiroshima University Hospital. All of the participants provided written informed consent. We examined patients who had experienced ischemic stroke at least 6 months before the onset of the study and patients with one or more risk factors for stroke at our hospital from December 2011 to June 2012. All patients were more than 20 years old. Three subtypes of ischemic stroke were classified using the Trial of Org 10172 in Acute Stroke Treatment criteria: large artery atherosclerosis, cardioembolism, and small vessel occlusion. ${ }^{20}$ Patients who had experienced stroke of other determined etiology or stroke of undetermined etiology were excluded from this study. The risk factors for stroke were defined as hypertension, diabetes mellitus, dyslipidemia, and atrial fibrillation, and hypertension, diabetes mellitus, and dyslipidemia were diagnosed by physicians. Patients were designated as hypertensive if they were taking antihypertensive agents and had a systolic blood pressure of $140 \mathrm{~mm} \mathrm{Hg}$ or more and/or a diastolic blood pressure of $90 \mathrm{~mm} \mathrm{Hg}$ or more. Patients were diagnosed with diabetes mellitus if they were treated with oral hypoglycemic agents or insulin and/or if their serum fasting blood glucose level was $126 \mathrm{mg} / \mathrm{dL}$ or more or hemoglobin A1c by the National Glycohemoglobin Standardization Program was $6.5 \%$ or more. Patients were diagnosed with dyslipidemia if they were taking antidyslipidemia medication or presented with a serum lowdensity lipoprotein cholesterol level of $3.62 \mathrm{mmol} / \mathrm{L}$ or more, a triglyceride level of $3.879 \mathrm{mmol} / \mathrm{L}$ or more and/or a high-density lipoprotein cholesterol level of less than $1.034 \mathrm{mmol} / \mathrm{L}$. Patients with malignancy or immunological disorders, including vasculitis, were excluded. Patient disability was evaluated using the modified Rankin Scale.

Patient blood samples were collected within 1 month of carotid ultrasonography. The blood parameters were as follows: the platelet count, hemoglobin, fibrinogen, C-reactive protein, low-density lipoprotein cholesterol, high-density lipoprotein cholesterol, hemoglobin A1c, blood urea nitrogen, creatinine, the estimated glomerular filtration rate, and the numbers of CECs and EPCs. The estimated glomerular filtration rate $(\mathrm{mL} / \mathrm{minute} /$ $1.73 \mathrm{~m}^{2}$ ) was calculated using the following equation: $194 \times$ serum creatinine $e^{(-1.094)} \times$ age $^{(-.287)} \times .739$ (if female). ${ }^{21}$

Ultrasound examinations of carotid arteries were performed using an SSA-770A imaging system (Toshiba, Tokyo, Japan) with a 5-11 MHz linear array transducer. Seven investigators (A.H., I.T., T.M., T.O., M.N., T.N., and T.N.) obtained the ultrasonographic images. The maximum and mean IMTs of the common carotid artery (CCA) were measured by 1 investigator (T.S.) using an IntimaScope (Media Cross, Tokyo, Japan) at the $\mathrm{R}$ wave of the electrocardiogram. The maximum IMT of CCA was defined as the maximum IMT value at the far wall. The mean IMT of CCA was defined as the average of IMT measurements along a 20-mm-long section, including the maximum IMT, and was measured 3 times on each side. The severity of carotid atherosclerosis in each patient was evaluated using the plaque score, as follows: none (IMT $<1.1 \mathrm{~mm}$ ), mild (plaque score $\leq 5$ ), moderate $(5<$ plaque score $\leq 10)$, and severe (plaque score $>10) .{ }^{22}$ Patients who had plaque scores that were obviously more than 10 but who could not be assigned an exact score because of calcification, occlusion, or image quality were designated as having severe atherosclerosis.

Fluorescence-activated cell analysis was performed to determine the numbers of CECs and EPCs using a single platform and a lyse-no-wash procedure, as previously reported. ${ }^{23-26}$ We defined CECs as CD34+/CD144+ cells and EPCs as CD34+/CD133+ cells. Briefly, 4 tubes containing $200 \mu \mathrm{L}$ peripheral venous whole blood with ethylenediamine tetraacetic acid-2Na (VP-NA052K; Terumo, Tokyo, Japan) were incubated in $10 \mu \mathrm{L} \mathrm{FcR}$ Blocking Reagent (130-059-901; Miltenyi Biotec, Bergisch Gladbach, Germany) for 10 minutes on ice. Thereafter, 

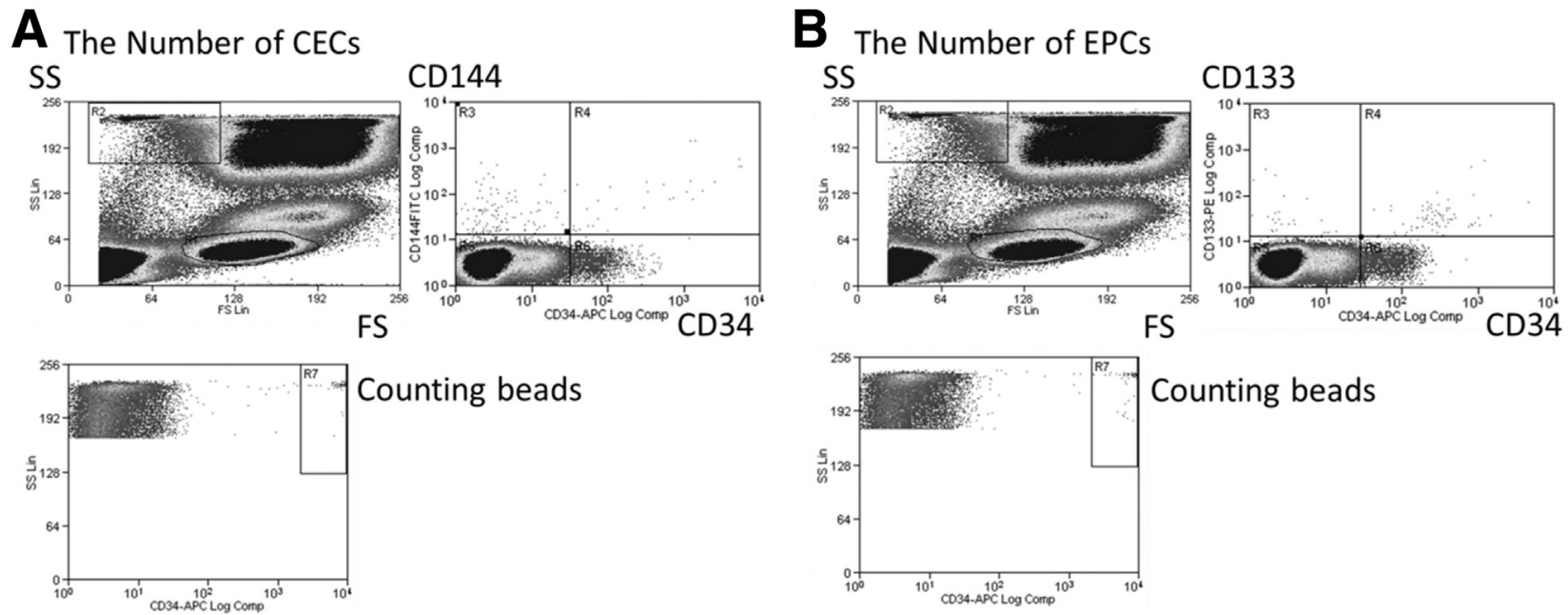

Figure 1. The gating strategy for CEC and EPC identification by flow cytometry. (A) The strategy for gating CD34+/CD144+ cells (CECs) was as follows: (1) lymphocyte area from FS and SS (R1) and (2) CD34+/CD144+ (R4). (B) The strategy for gating CD34+/CD133+ cells (EPCs) was as follows: (1) lymphocyte area from FS and SS (R1) and (2) CD34+/CD133+ (R4). The strategy for gating the counting beads was as follows: R2 and R7. Abbreviations: CECs, circulating endothelial cells; EPCs, endothelial progenitor cells; FS, forward scatter; SS, side scatter.

the tubes were incubated on ice in the dark for 30 minutes, with 2 tubes containing $5 \mu \mathrm{L}$ allophycocyanin-labeled antiCD34 antibody (IM2472U; Beckman Coulter, Marseille, France) and $10 \mu \mathrm{L}$ fluorescein isothiocyanate-labeled antiCD144 antibody (560411; BD Biosciences, San Diego, CA) and 2 tubes containing $5 \mu \mathrm{L}$ allophycocyanin-labeled anti-CD34 antibody and $5 \mu \mathrm{L}$ phycoerythrin-labeled antiCD133 antibody (130-080-801; Miltenyi Biotec). To lyse the red blood cells, $1 \mathrm{~mL}$ lysis buffer (A09777; Beckman Coulter) was added to the tubes and incubated on ice in the dark at room temperature $\left(18^{\circ} \mathrm{C}-25^{\circ} \mathrm{C}\right)$. The samples were then filtered through a $35 \mu \mathrm{m}$ cell strainer (352235; BD Biosciences) into $5 \mathrm{~mL}$ test tubes (A26428; Beckman Coulter). To count the absolute number of CECs or EPCs, $50 \mu \mathrm{L}$ counting beads (C36950; Life Technologies, Carlsbad, CA) was added to the test tubes. The analysis was performed with an automated fluorescence-activated cell counter (CyAn ADP; Beckman Coulter). The gating strategy is illustrated in Figure 1. In total, 20,000-21,000 events in the gate for counting beads were counted. The absolute CEC or EPC count (cells $/ \mu \mathrm{L}$ ) was then calculated as follows: (the number of target cell events/the number of counting beads) $\times$ (the assigned bead count of the lot $/ 200 \mu \mathrm{L}$ ). The means of 2 measurements were calculated for both CECs and EPCs. One investigator (T.S.) prepared all samples. The average coefficient of variance in 5 consecutive volunteers ( 3 men and 2 women; $30-34$ years old) was $8.3 \%$ for the number of EPCs and $10.6 \%$ for the number of CECs. The average coefficient of variance between 0 and 4 hours from blood collection to initiate procedure for the methods of counting EPCs and CECs in the same blood specimen was $4.4 \%$ for the number of EPCs and 3.6\% for the number of CECs.

Age, gender, height, weight, body mass index, systolic blood pressure, diastolic blood pressure, pulse rate, smoking within 1 year, and the modified Rankin Scale score were determined for each participant.

The data are expressed as the mean \pm standard deviation for continuous variables. Statistical analyses were performed with IBM, version 19 (IBM, Chicago, IL). The Kruskal-Wallis test and the Mann-Whitney $U$ test were used to detect significant differences, as appropriate. The coefficient of determination, which is the square of Spearman correlation coefficient, was used to verify the associations between the number of CECs or EPCs and carotid atherosclerosis (eg, the mean IMT of CCA and the plaque score). A multifactorial regression analysis with forced entry was also performed to verify the associations between the number of CECs or EPCs and the white blood cell count after adjustment for the participants' age, gender, height, weight, and systolic blood pressure.

\section{Results}

A total of 45 patients with chronic ischemic stroke were included in this study: 18 with large artery atherosclerosis (70.9 \pm 7.5 years, 3 women), 18 with cardioembolism (67.6 \pm 12.4 years, 10 women), 9 with small vessel occlusion ( $69.0 \pm 12.2$ years, 3 women), and 13 with risk factors for stroke (70.9 \pm 8.2 years, 5 women). The baseline characteristics of the participants are presented in Table 1. Significant differences in systolic blood pressure, diabetes mellitus, and atrial fibrillation were noted between stroke subtypes. There was 1 case of carotid artery stenting. There was no plaque in 14 patients, whereas a plaque score could be calculated in 36 patients. Moreover, 6 patients were designated as having severe atherosclerosis because of their severe carotid artery stenosis, occlusion, and post-carotid artery stenting, although their plaque 
Table 1. Baseline characteristics of the study participants

\begin{tabular}{|c|c|c|c|c|c|c|}
\hline Parameter & Total & $\begin{array}{l}\text { Large artery } \\
\text { atherosclerosis }\end{array}$ & Cardioembolism & $\begin{array}{c}\text { Small vessel } \\
\text { occlusion }\end{array}$ & Risk factors & $P$ value \\
\hline $\mathrm{N}$ & 58 & 18 & 18 & 9 & 13 & \\
\hline Gender, M/F & $37 / 21$ & $15 / 3$ & $8 / 10$ & $6 / 3$ & $8 / 5$ & .119 \\
\hline Age, y & $69.6 \pm 10.0$ & $70.9 \pm 7.5$ & $67.6 \pm 12.4$ & $69.0 \pm 12.2$ & $70.9 \pm 8.2$ & .642 \\
\hline Height, $m$ & $1.62 \pm .09$ & $1.63 \pm .09$ & $1.60 \pm .09$ & $1.64 \pm .09$ & $1.60 \pm .07$ & .456 \\
\hline Weight, kg & $63.5 \pm 11.0$ & $66.1 \pm 10.9$ & $63.2 \pm 11.2$ & $60.4 \pm 13.3$ & $62.3 \pm 9.6$ & .573 \\
\hline BMI, $\mathrm{kg} / \mathrm{m}^{2}$ & $24.2 \pm 3.3$ & $24.8 \pm 3.3$ & $24.5 \pm 3.0$ & $22.4 \pm 3.8$ & $24.3 \pm 3.0$ & .449 \\
\hline Hypertension, \pm & $39 / 19$ & $14 / 4$ & $9 / 9$ & $6 / 3$ & $10 / 3$ & .281 \\
\hline $\mathrm{SBP}, \mathrm{mm} \mathrm{Hg}$ & $136.9 \pm 19.3$ & $146.4 \pm 13.3$ & $127.1 \pm 18.5$ & $126.8 \pm 18.6$ & $144.3 \pm 19.5$ & $<.01$ \\
\hline $\mathrm{DBP}, \mathrm{mm} \mathrm{Hg}$ & $76.7 \pm 12.5$ & $78.7 \pm 14.1$ & $73.9 \pm 12.2$ & $71.0 \pm 9.3$ & $81.8 \pm 10.9$ & .126 \\
\hline Pulse rate, counts/min & $76.2 \pm 12.8$ & $76.4 \pm 12.8$ & $75.5 \pm 13.4$ & $72.9 \pm 12.0$ & $79.4 \pm 13.1$ & .723 \\
\hline Diabetes mellitus, \pm & $17 / 41$ & $10 / 8$ & $4 / 14$ & $3 / 6$ & $0 / 13$ & $<.01$ \\
\hline Dyslipidemia, \pm & $39 / 19$ & $16 / 2$ & $6 / 12$ & $8 / 1$ & $9 / 4$ & $<.01$ \\
\hline Atrial fibrillation, \pm & $16 / 42$ & $0 / 18$ & $14 / 4$ & $0 / 9$ & $2 / 11$ & $<.001$ \\
\hline Smoking within $1 \mathrm{y}, \pm$ & $5 / 53$ & $4 / 14$ & $1 / 17$ & $0 / 9$ & $0 / 13$ & .093 \\
\hline mRS score, median (IQR) & $1(1-1)$ & $1(1-1.5)$ & $1(1-1.5)$ & $1(1-1)$ & $1(1-1)$ & .825 \\
\hline White blood cell count, cells $/ \mu \mathrm{L}$ & $6242 \pm 1565$ & $6792 \pm 1430$ & $5549 \pm 1853$ & $6751 \pm 1190$ & $6088 \pm 1238$ & $<.05$ \\
\hline Platelet count, counts $/ \mu \mathrm{L}$ & $20.2 \pm 5.3$ & $21.7 \pm 4.4$ & $19.1 \pm 6.6$ & $20.2 \pm 5.5$ & $19.4 \pm 4.2$ & .293 \\
\hline Hemoglobin, g/L & $139 \pm 17$ & $145 \pm 21$ & $133 \pm 19$ & $136 \pm 11$ & $140 \pm 9$ & .306 \\
\hline Fibrinogen, $\mathrm{g} / \mathrm{L}$ & $3.13 \pm .68$ & $3.27 \pm .47$ & $3.23 \pm .69$ & $3.26 \pm .89$ & $2.73 \pm .68$ & .214 \\
\hline C-reactive protein, $\mu \mathrm{g} / \mathrm{L}$ & $3500 \pm 10000$ & $4800 \pm 15600$ & $4900 \pm 8800$ & $1500 \pm 2000$ & $1000 \pm 1500$ & .570 \\
\hline LDL cholesterol, mmol/L & $3.057 \pm .802$ & $3.002 \pm .711$ & $3.227 \pm 1.076$ & $2.956 \pm .577$ & $2.971 \pm .644$ & .687 \\
\hline HDL cholesterol, mmol/L & $1.567 \pm .372$ & $1.533 \pm .427$ & $1.531 \pm .334$ & $1.702 \pm .357$ & $1.575 \pm .380$ & .702 \\
\hline $\mathrm{HbA} 1 \mathrm{c}, \%$ & $6.18 \pm .75$ & $6.48 \pm .83$ & $6.18 \pm .85$ & $6.03 \pm .60$ & $5.85 \pm .37$ & .256 \\
\hline $\mathrm{BUN}, \mathrm{mmol} / \mathrm{L}$ & $6.07 \pm 2.11$ & $6.00 \pm 2.50$ & $5.64 \pm 1.96$ & $7.14 \pm 2.21$ & $6.03 \pm 1.61$ & .273 \\
\hline Creatinine, $\mu \mathrm{mol} / \mathrm{L}$ & $88.4 \pm 101.7$ & $114.9 \pm 164.4$ & $65.4 \pm 16.8$ & $105.2 \pm 105.2$ & $72.5 \pm 16.8$ & .130 \\
\hline $\mathrm{eGFR}, \mathrm{mL} / \mathrm{min}$ & $67.5 \pm 19.7$ & $63.2 \pm 19.6$ & $72.9 \pm 16.6$ & $65.8 \pm 30.5$ & $67.1 \pm 14.4$ & .597 \\
\hline Carotid atherosclerosis, $\mathrm{n}$ & & & & & & .058 \\
\hline No plaque & 14 & 1 & 6 & 3 & 4 & \\
\hline Mild & 20 & 6 & 6 & 5 & 3 & \\
\hline Moderate & 12 & 4 & 5 & 0 & 3 & \\
\hline Severe & 10 & 6 & 1 & 1 & 2 & \\
\hline Unknown & 2 & 1 & 0 & 0 & 1 & \\
\hline
\end{tabular}

Abbreviations: BMI, body mass index; BUN, blood urea nitrogen; DBP, diastolic blood pressure; eGFR, estimated glomerular filtration rate; HbA1c, hemoglobin A1c; HDL, high-density lipoprotein; IQR, interquartile range; LDL, low-density lipoprotein; mRS, modified Rankin Scale; SBP, systolic blood pressure.

The data are represented as mean \pm standard deviation unless otherwise mentioned.

scores could not be calculated. Two patients were excluded from the analysis of atherosclerosis because their plaque scores could not be calculated exactly (one had large artery atherosclerosis, and one had risk factors for stroke).

The relationship between the number of CECs or EPCs and the white blood cell count after adjustment for age, gender, height, weight, and systolic blood pressure was investigated by multifactorial regression analysis with forced entry (Table 2). The white blood cell count was strongly associated with the number of CECs or EPCs, even after adjustment.

The number of CECs in patients with large artery atherosclerosis was higher than that in patients with cardioembolism or small vessel occlusion $(P<.05$, Fig $2, \mathrm{~A})$. In contrast, there were no significant differences in the number of EPCs between groups. No correlation was observed between the mean IMT of CCA and the number of CECs or EPCs (Fig 3, A,B). No correlation was observed between the maximum IMT of CCA and the number of CECs or EPCs. A positive correlation was observed between the plaque score and the number of CECs ( $\mathrm{n}=36$, $\mathrm{r}^{2}=.139, P<.05$, Fig $3, \mathrm{C}$ ). The number of CECs in patients with moderate and severe atherosclerosis was higher than that in patients with no plaque and mild atherosclerosis (no plaque and mild, .25 $\pm .07 / \mu \mathrm{L}, \mathrm{n}=34$; moderate and severe, $.32 \pm .11 / \mu \mathrm{L}, \mathrm{n}=22 ; P<.05$; Fig 4 ).

\section{Discussion}

In this study, we evaluated the relationship between the number of CECs or EPCs, determined using flow 
Table 2. Relationship between the number of CECs or EPCs and the WBC count

\begin{tabular}{|c|c|c|c|c|c|c|c|c|c|c|c|}
\hline & \multirow[b]{2}{*}{ Parameter } & \multicolumn{5}{|c|}{ The number of CECs } & \multicolumn{5}{|c|}{ The number of EPCs } \\
\hline & & $\begin{array}{l}\text { Standard partial } \\
\text { regression } \\
\text { coefficient }\end{array}$ & $P$ value & $F$ & $P$ value & Adjusted $R^{2}$ & $\begin{array}{c}\text { Standard partial } \\
\text { regression } \\
\text { coefficient }\end{array}$ & $P$ value & $F$ & $P$ value & Adjusted $R^{2}$ \\
\hline \multirow[t]{2}{*}{1} & Unadjusted & & & & & & & & & & \\
\hline & WBC & .54 & $<.001$ & 22.5 & $<.001$ & .274 & .49 & $<.001$ & 20.4 & $<.001$ & .254 \\
\hline \multirow[t]{4}{*}{2} & Adjusted 1 & & & & & & & & & & \\
\hline & WBC & .54 & $<.001$ & 7.3 & $<.001$ & .249 & .51 & $<.001$ & 8.1 & $<.001$ & .273 \\
\hline & Age & .02 & .83 & & & & -.16 & .17 & & & \\
\hline & Gender & .03 & .82 & & & & -.14 & .21 & & & \\
\hline \multirow[t]{7}{*}{3} & Adjusted 2 & & & & & & & & & & \\
\hline & WBC & .53 & $<.001$ & 5.4 & $<.001$ & .317 & .56 & $<.001$ & 5.7 & $<.001$ & .331 \\
\hline & Age & -.12 & .37 & & & & -.14 & .28 & & & \\
\hline & Gender & -.18 & .29 & & & & -.03 & .86 & & & \\
\hline & Height & -.42 & .02 & & & & -.15 & .39 & & & \\
\hline & Weight & .10 & .50 & & & & .33 & .03 & & & \\
\hline & SBP & .14 & .24 & & & & .15 & .21 & & & \\
\hline
\end{tabular}

Abbreviations: CECs, circulating endothelial cells; EPCs, endothelial progenitor cells; SBP, systolic blood pressure; WBC, white blood cell count.

Adjusted 1 = adjusted for WBC, age, and gender. Adjusted 2 = adjusted for WBC, age, gender, height, weight, and SBP.

cytometry, and indicators of carotid atherosclerosis in patients with chronic ischemic stroke and in patients with risk factors for stroke. The number of CECs was associated with the plaque score, which is an indicator of atherosclerosis, and was highest in patients with large artery atherosclerosis.

The number of CECs in patients with large artery atherosclerosis was also higher than that in patients with other types of ischemic stroke. A previous study showed that the number of CECs, which were detected as CD146+ cells using magnetic beads, was not significantly different between the subtypes of acute ischemic stroke patients. ${ }^{27}$ Another study examining acute ischemic stroke also showed that there was no association between $\mathrm{CD} 34+$ cells and the plaque score. ${ }^{19}$ In the present study, the number of CD34+/CD144+ cells, which were defined as CECs, was associated with the plaque score and was higher in patients with moderate and severe atherosclerosis than in patients with no plaque and mild atherosclerosis. Thus, the number of CECs is higher in more severe forms of carotid atherosclerosis. CD34+ cells comprise many cell types, including both EPCs and CECs, so CD34+ cell subpopulations should be more finely separated by using other surface markers.
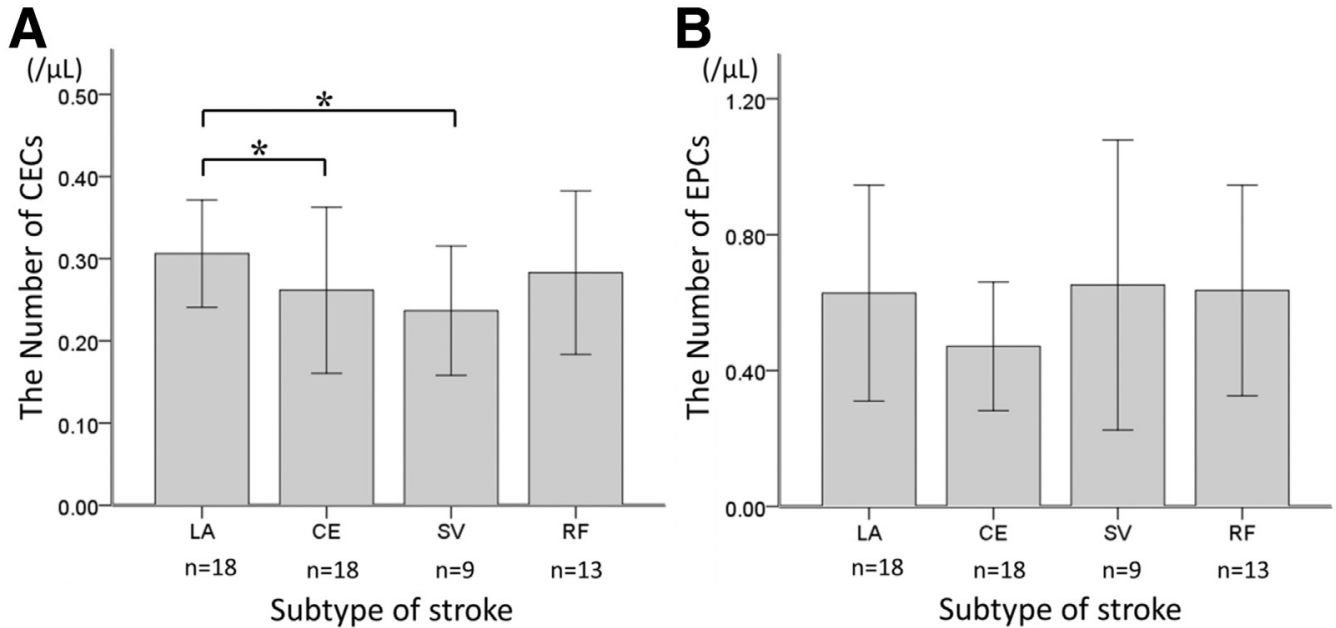

Figure 2. The numbers of CECS $(A)$ and EPCS $(B)$ in patients with chronic ischemic stroke and in patients with risk factors for stroke. ${ }^{*} \mathrm{P}<.05$ versus $L A$. Abbreviations: CE, cardioembolism; CECs, circulating endothelial cells; EPCs, endothelial progenitor cells; LA, large artery atherosclerosis; RF, risk factors; $S V$, small vessel occlusion. 
A

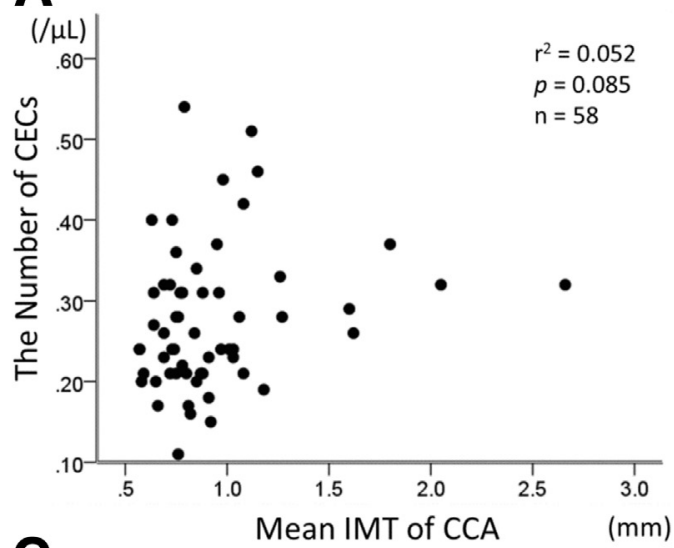

B

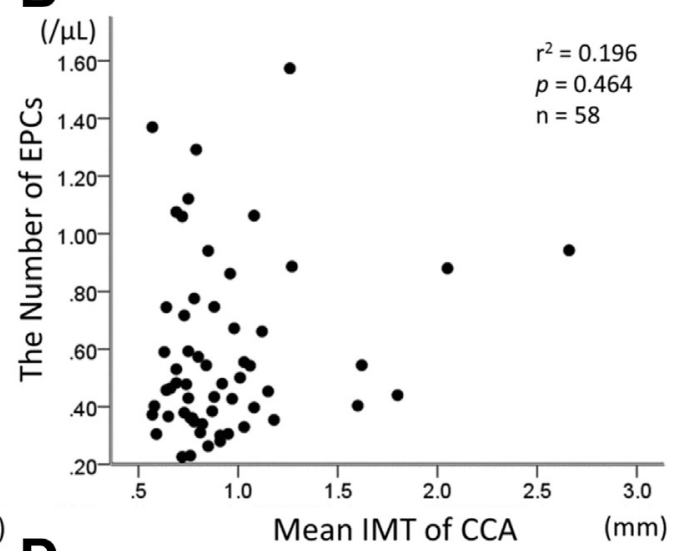

D

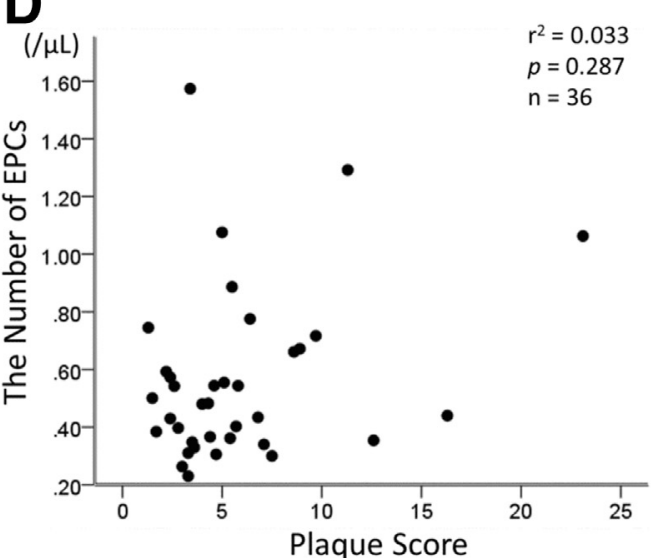

Figure 3. The relationship between the number of CECS or EPCS and parameters of carotid atherosclerosis. There was no linear relationship of mean IMT of CCA with the number of CECS $(A)$ and EPCs $(B)$. There was linear relationship of plaque score with the number of CECs $(C)$. There was no linear relationship of plaque score with the number of EPCs (D). Abbreviations: CCA, common carotid artery; CECs, circulating endothelial cells; EPCs, endothelial progenitor cells; IMT, intima-media thickness.

In the present study, we separated CD34+ cells into EPCs, using the markers CD34 and CD133, and CECs, using the markers CD34 and CD144. We determined that an increased number of CECs (CD34+/CD144+ cells)

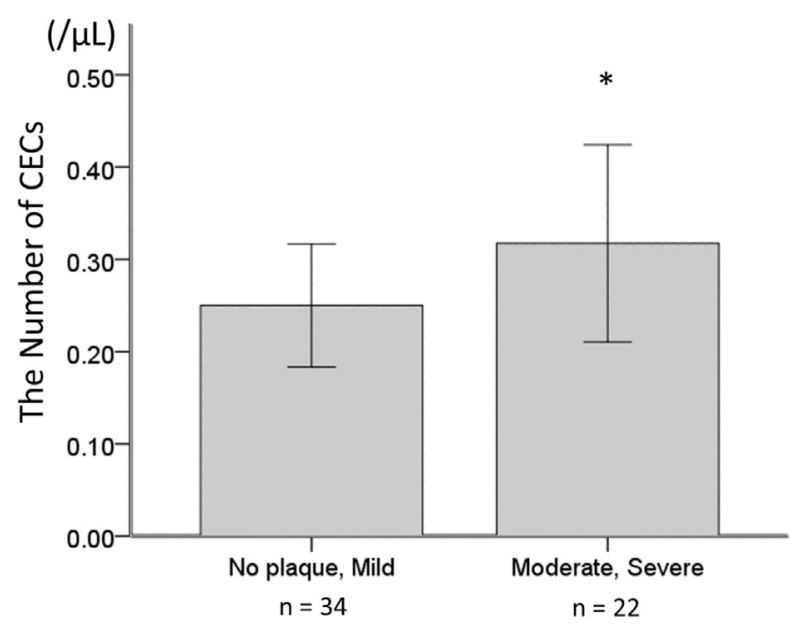

Figure 4. The relationship between the number of CECs and the severity of carotid atherosclerosis. *P $<.05$ compared with patients with no plaque and mild atherosclerosis. Abbreviation: CECS, circulating endothelial cells. were associated with carotid atherosclerosis. In our study, patients with large artery atherosclerosis had more severe atherosclerosis, which reflected the difference in the number of CECs in the subtypes of chronic ischemic stroke.

Both the number of CECs and the number of EPCs were correlated with the white blood cell count in our study. In contrast, no previous reports have evaluated an association of the number of CECs or EPCs with the white blood cell count. We counted the numbers of CECs and EPCs directly by flow cytometry, rather than counting them based on the white blood cell count. CECs and EPCs are both considered to be derived from the same origin of white blood cells, hemangioblasts ${ }^{28}$; so, the relationship between these cell types may mainly reflect the function of bone marrow. It shows that the number of EPCs may be more reflected in the function of bone marrow but not in the severity of carotid atherosclerosis. From our results, no correlation was observed between the IMT of CCA or the plaque score and the number of EPCs. The subjects, the definition of EPCs and the indicators of carotid atherosclerosis in our study were different from those of the previous studies that showed the correlation between the indicator of atherosclerosis and the number 
of EPCs. ${ }^{8,9}$ Fadini et $\mathrm{al}^{8}$ reported that the IMT of CCA was inversely correlated with the number of EPCs as CD34+/ $\mathrm{KDR}+$ cells but not with the number of EPCs as CD34+ / CD133+ cells, and the subjects with carotid plaque were excluded from their study. Hill et $\mathrm{al}^{9}$ reported that the FMD of brachial artery was correlated with the number of colony-forming units of EPCs in blood samples in the subjects with cardiovascular risk factors. In our study, the subjects had carotid plaque, and the EPCs were defined as CD34+/CD133+ cells. The different atherosclerosis indicators as the FMD of brachial artery, the IMT of CCA, and the plaque score may produce the difference in relations with the number of EPCs.

Our study has certain limitations. First, this study was performed at a single research facility, and the number of cases was limited. Further studies including more cases at multiple research facilities are needed. Second, we were not able to obtain a plaque score for all of the patients for technical reasons. Therefore, selection bias might exist. Finally, we did not evaluate the influence of drugs on the numbers of CECs and EPCs.

In conclusion, the number of CECs in patients with large artery atherosclerosis in the chronic phase was higher than that in patients with other types of stroke. The number of CECs was associated with the severity of carotid atherosclerosis.

Acknowledgment: We would like to sincerely thank Dr. Tomokazu Nishikawa, Dr. Masahiro Nakamori, Ms. Akemi Hironaka, Ms. Miwako Sasanishi, and Ms. Yasuko Furuno at Hiroshima University for their technical support. Additionally, we would like to sincerely thank Dr. Tomonori Hayashi at the Radiation Effects Research Foundation, Dr. Takeshi Nakamura at Oyamada Memorial Spa Hospital, and Dr. Tatsuo Kohriyama at Hiroshima City Rehabilitation Hospital for their insightful comments.

\section{References}

1. Blann AD, Pretorius A. Circulating endothelial cells and endothelial progenitor cells: two sides of the same coin, or two different coins? Atherosclerosis 2006;188:12-18.

2. Goon PKY, Lip GYH, Stonelake PS, et al. Circulating endothelial cells and circulating progenitor cells breast cancer: relationship to endothelial damage/dysfunction/apoptosis, clinicopathologic factors, and the Nottingham Prognostic Index. Neoplasia 2009;11:771-779.

3. Woywodt A, Goldberg C, Kirsch T, et al. Circulating endothelial cells in relapse and limited granulomatous disease due to ANCA associated vasculitis. Ann Rheum Dis 2006;65:164-168.

4. Asahara T, Murohara T, Sullivan A, et al. Isolation of putative progenitor endothelial cells for angiogenesis. Science 1997;275:964-967.

5. Wisemann S, Marlborough F, Doubal F, et al. Blood markers of coagulation, fibrinolysis, endothelial dysfunction and inflammation in lacunar stroke versus nonlacunar stroke and non-stroke: systematic review and meta-analysis. Cerebrovasc Dis 2014;37:64-75.
6. Hosomi N, Aoki S, Matsuo K, et al. Association of serum anti-periodontal pathogen antibody with ischemic stroke. Cerebrovasc Dis 2012;34:385-392.

7. Nezu T, Hosomi N, Aoki S, et al. Alpha2-macroglobulin as a promising biomarker for cerebral small vessel disease in acute ischemic stroke patients. J Neurol 2013; 260:2642-2649.

8. Fadini GP, Coracina A, Baesso I, et al. Peripheral blood CD34+KDR + endothelial progenitor cells are determinants of subclinical atherosclerosis in a middle-aged general population. Stroke 2006;37:2277-2282.

9. Hill JM, Zalos G, Halcox JP, et al. Circulating endothelial progenitor cells, vascular function, and cardiovascular risk. N Engl J Med 2003;348:593-600.

10. Grobbee DE, Bots ML. Carotid artery intima-media thickness as an indicator of generalized atherosclerosis. J Intern Med 1994;236:567-573.

11. Hosomi N, Mizushige K, Ohyama H, et al. Angiotensinconverting enzyme inhibition with enalapril slows progressive intima-media thickening of the common carotid artery in patients with non-insulin-dependent diabetes mellitus. Stroke 2001;32:1539-1545.

12. Persson J, Formgren J, Israelsson B, et al. Ultrasounddetermined intima-media thickness and atherosclerosis. Direct and indirect validation. Arterioscler Thromb 1994; 14:261-264.

13. Burke GL, Evans GW, Riley WA, et al. Arterial wall thickness is associated with prevalent cardiovascular disease in middle-aged adults. The Atherosclerosis Risk in Communities (ARIC) Study. Stroke 1995;26: 386-391.

14. Allan PL, Mowbray PI, Lee AJ, et al. Relationship between carotid intima-media thickness and symptomatic and asymptomatic peripheral arterial disease. The Edinburgh Artery Study. Stroke 1997;28:348-353.

15. Salonen JT, Salonen R. Ultrasound B-mode imaging in observational studies of atherosclerotic progression. Circulation 1993;87:II56-II65.

16. Bots ML, Hoes AW, Koudstaal PJ, et al. Common carotid intima-media thickness and risk of stroke and myocardial infarction: the Rotterdam Study. Circulation 1997;96: 1432-1437.

17. Nagai $Y$, Matsumoto $M$, Metter EJ. The carotid artery as a noninvasive window for cardiovascular risk in apparently healthy individuals. Ultraound Med Biol 2002; 28:1231-1238.

18. Gao Y, Liu C, Zhang X, et al. Circulating endothelial cells as potential markers of atherosclerosis. Can J Neurol Sci 2008;35:638-642.

19. Taguchi A, Matsuyama T, Moriwaki H, et al. Circulating CD34-positive cells provide an index of cerebrovascular function. Circulation 2004;109:2972-2975.

20. Adams HP Jr, Bendixen BH, Kappelle LJ, et al. Classification of subtype of acute ischemic stroke. Definitions for use in a multicenter clinical trial. TOAST. Trial of Org 10172 in Acute Stroke Treatment. Stroke 1993;24: 35-41.

21. Matsuo S, Imai E, Horio M, et al. Revised equations for estimated GFR from serum creatinine in Japan. Am J Kidney Dis 2009;53:982-992.

22. Handa N, Matsumoto M, Maeda $\mathrm{H}$, et al. Ultrasonic evaluation of early carotid atherosclerosis. Stroke 1990; 21:1567-1572.

23. Duda DG, Cohen KS, Scadden DT, et al. A protocol for phenotypic detection and enumeration of circulating endothelial cells and circulating progenitor cells in human blood. Nat Protoc 2007;2:805-810. 
24. Sutherland DR, Anderson L, Keeney M, et al. The ISHAGE guidelines for CD34+ cell determination by flow cytometry. International Society of Hepatotherapy and Graft Engineering. J Hematother 1996;5:213-226.

25. Japanese Committee for Clinical Laboratory Standards. Guidelines for performing surface antigen analysis on hematopoietic malignant cells (JCCLS H2-p V1.0). Rinsho Byori 2003;51:910-926.

26. Ozdogu H, Sozer O, Boga C, et al. Flow cytometric evaluation of circulating endothelial cells: a new protocol for identifying endothelial cells at several stages of differentiation. Am J Hematol 2007;82:706-711.

27. Woywodt A, Gerdes S, Bjoern A, et al. Circulating endothelial cells and stroke: influence of stroke subtypes and changes during the course of disease. J Stroke Cerebrovasc Dis 2012;21:452-458.

28. Pelosi E, Castelli G, Martin-Padura I, et al. Human haemato-endothelial precursors: cord blood CD34+ cells produce haemogenic endothelium. PLoS One 2012;7: e51109. 